ERRATUM

Jane Zochling • Martin H. J. Bohl-Bühler •

Xenofon Baraliakos · Ernst Feldtkeller · Jürgen Braun

\title{
The high prevalence of infections and allergic symptoms in patients with ankylosing spondylitis is associated with clinical symptoms
}

The authors regret the following errors:

Table 1: The 220 AS patients with skin rash represent $20.4 \%$ of the cohort, not $27.5 \%$.

Subsection "Factors associated with infection and allergy in ankylosing spondylitis": The first sentence should read "Women were more likely to report infection than men" (not "almost twice as likely").

Figure 3: The portion of patients with pain more than $12 \mathrm{~h}$ a day among AS patients with no infection was $45 \%$ (not $36 \%$ as shown in the figure), compared to $52 \%$ among AS patients with any infection ( $p 0.05)$.
Table 2: The last item in the footnote should read " $O R$ odds ratio", not $O D$.

Appendix, Question 17: An additional option "More than 2 hours per day" was offered.

Reference 19: "van der HD" should be "van der Heijde D", and "van der LS" should be "van der Linden S".

Reference 21: "Murbus" should be "Morbus".

Reference 42: "van der LS" should be "van der Linden S".

Reference 45: "van den BF" should be "van den Bosch F" and "van den BN" should be "van den Bossche N".

The online version of the original article can be found at: http://dx. doi.org/10.1007/s10067-005-0130-0

\footnotetext{
J. Zochling $\cdot$ X. Baraliakos $\cdot$ J. Braun $(\bowtie)$

Rheumazentrum Ruhrgebiet, St. Josefs-Krankenhaus,

Landgrafenstr, 15,

44652 Herne, Germany

e-mail: J.Braun@rheumazentrum-ruhrgebiet.de

Tel.: +49-2325-592131

Fax: +49-2325-592136

M. H. J. Bohl-Bühler

KB-Practice for internal medicine,

Brandenburg, Germany

E. Feldtkeller

Ankylosing Spondylitis International Federation,

Munich, Germany
} 